\title{
THE PURE SLIDING COLLAPSE MODE OF NON-SYMMETRIC MASONRY ARCHES: A CRITICAL REVIEW OF MONASTERIO'S CONTRIBUTION AND AN ALTERNATIVE FORMULATION
}

\author{
Danila Aita $^{1}$, Anna Sinopoli ${ }^{2}$ \\ ${ }^{1}$ Department of Civil and Industrial Engineering, University of Pisa \\ Largo Lucio Lazzarino 2 - 56122 Pisa (Italy) \\ e-mail: danila.aita@unipi.it \\ ${ }^{2}$ Department of Structural and Geotechnical Engineering, Sapienza University of Rome \\ Via Gramsci 53 - 00197 Rome (Italy) \\ anna.sinopoli@uniroma1.it
}

\begin{abstract}
Aim of the present paper is to analyze and revisit the first chapter of the Monasterio's unpublished manuscript where the pure sliding collapse mode of non-symmetric masonry arches is investigated. As it will be shown, the Monasterio approach is of a "kinematical" type, since the collapse mechanisms are "a priori" selected and, then, some criterion is adopted to identify the collapse condition. In the present study, it will be shown that the basic assumptions of the Monasterio's analysis are fully in agreement with the modern limit analysis. Furthermore, an alternative formulation for the assessment of the equilibrium of non-symmetric arches is given.
\end{abstract}

Keywords: Non-symmetric masonry arches, Coulomb friction, Limit analysis, Upper bound approach, Pure sliding collapse mode. 


\section{INTRODUCTION}

The current paper constitutes the first step of a research project directed by Anna Sinopoli, undertaken by the Authors in response to Santiago Huerta's invitation. The main purpose of this project is to perform a critical analysis on the validity and advantage of the approach proposed by Monasterio in his unpublished manuscript, entitled Nueva teórica sobre el empuje de bóvedas [New theory on the thrust of vaults]. This interesting text was probably written in Spain around 1805 and 1806, when the development of pre-elastic historical theories on masonry arches was almost concluded. It was found by Santiago Huerta in the Library of the Escuela de Ingenieros de Caminos, Canales y Puertos of the Universidad Politécnica de Madrid, where Monasterio was professor of civil engineering, and was firstly introduced in the contemporary scientific literature in 2003 [1].

The collapse analysis of non-symmetric arches is the most challenging subject examined in Monasterio's contribution. It is a subject almost never investigated in the historical literature on masonry vaulted structures.

The present paper provides a critical review of the first Chapter of Nueva teórica, by focusing on the analysis of the pure sliding collapse mode of non-symmetric masonry arches.

\section{MONASTERIO'S KINEMATICAL APPROACH}

In his Introducción, Monasterio states that the search for the collapse condition must be carried out «por medio de la doctrina de máximos y mínimos, y no valiéndose, como se ha hecho comúnmente, de observaciones prácticas». Monasterio acknowledges the Coulomb's primacy, as already pointed out by Huerta and Foce [1]. His hypotheses regarding the masonry material coincide with Coulomb's hypotheses: i.e. the masonry is characterized by an infinite compressive strength, a nil tensile strength, and a limited friction coefficient [2-4]. Nevertheless, as it will be demonstrated, the approach he proposes is quite different from the Coulomb's method.

Namely, before beginning his investigation, Monasterio lists the possible collapse mechanisms occurring in a non-symmetric arch: his approach is therefore framed in the philosophy of the upper bound theorem $[5,6]$.

Monasterio does not develop any rigorous kinematic analysis (i.e. he does not analyze the possible relative displacements of the various voussoirs in agreement to the impenetrability law at each joint). His analysis seems to be of a qualitative nature; anyway it allows for identifying seven possible collapse modes occurring in a non-symmetrical arch, illustrated in Figure 1. The first one corresponds to the collapse by translation of two voussoirs (Plate I, Fig. $1^{\mathrm{a}}$ ); the second corresponds to the collapse by rotation of three voussoirs (Plate I, Fig. $2^{\mathrm{a}}$ ); finally, the last five correspond to collapse modes of a mixed type, involving both translation and rotation of either two or three voussoirs (Plate I, Figs. $3^{\mathrm{a}}-7^{\mathrm{a}}$ ). 


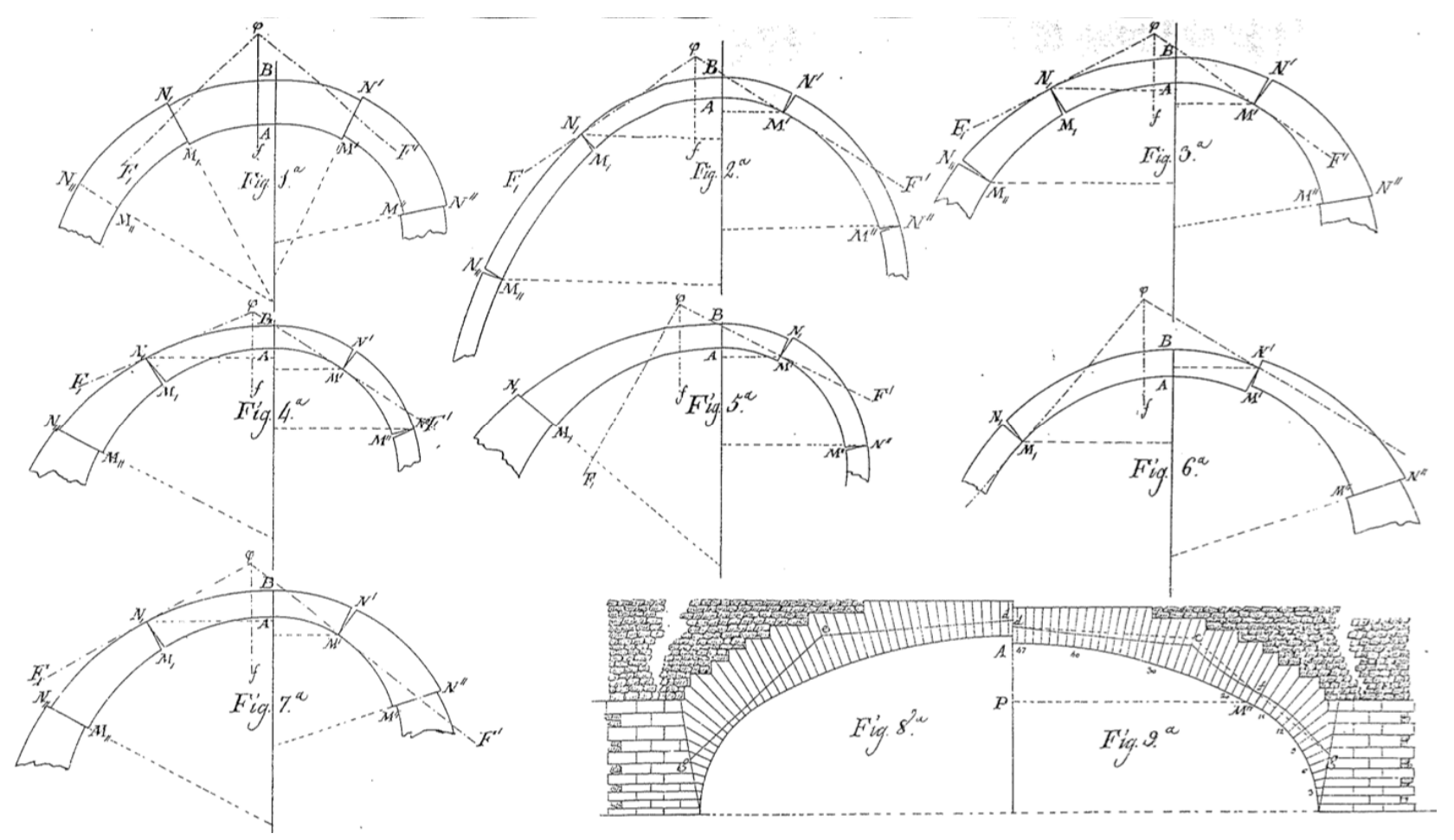

Fig. 1. Plate I of the Monasterio's manuscript.

\section{THE ANALYSIS OF THE PURE SLIDING MECHANISM ACCORDING TO MONASTERIO}

\subsection{The theoretical assumptions}

In the present paper the pure sliding collapse mode discussed in chapter I of Monasterio's manuscript is examined (Figure 2a, corresponding to Figure $1^{\mathrm{a}}$ of Monasterio's Plate I). According to this collapse mode, the left-hand voussoir containing the key joint slides inwards, while the one on right slides outwards, without any a priori assumption on the bounding joints position.

We adopt the same notation introduced by Monasterio in order to compare the procedure and results. The unknown joints candidates for sliding are identified by angles $\alpha_{i}, \alpha^{\prime}$ and $\alpha$ " (Fig. 2b), measured with respect to the vertical line associated with an absolute Cartesian system $(x, y)$. The $y$ axis passes through point $A$, located at the highest position of the intrados line. From now on, reference will be made to segment $A B$ (Fig. 2a) as the key joint of the arch. By examining Fig. 2b, it can be observed that the angles, considered as positive, are instead counted according to a clockwise rotation versus ( $\alpha^{\prime}$ and $\left.\alpha^{\prime \prime}\right)$, and counter-clockwise versus $\left(\alpha_{i}\right)$. The weights, $M_{i}$ and $M^{\prime}$, of the two parts in which the voussoir $N^{\prime} M^{\prime} M_{i} N_{i}$ is divided by the vertical axis $y$ depend on $\alpha_{i}$ and $\alpha$, respectively. 


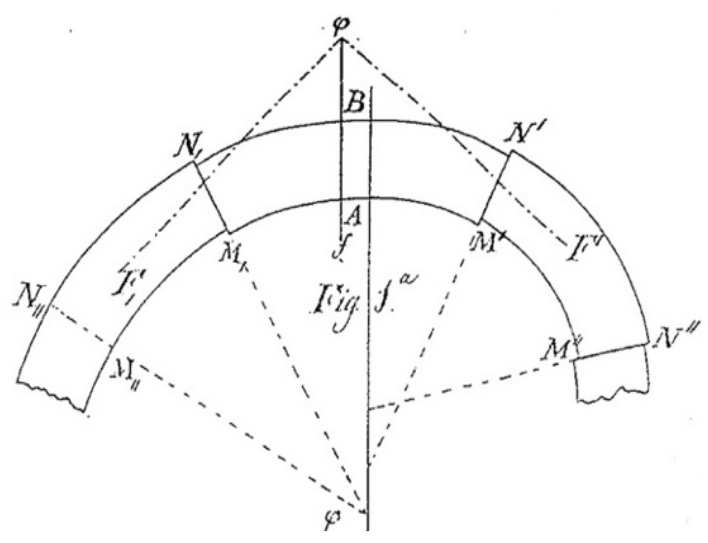

(a)

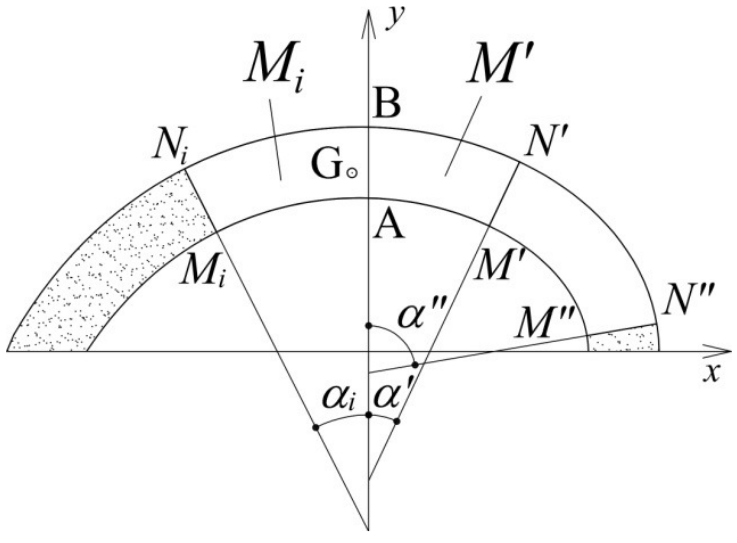

(b)

Fig. 2. The pure sliding mechanism according to Monasterio (a); the notation adopted by Monasterio (b).

Monasterio proposes the following procedure: by starting from any point $\varphi$ (Fig. 2a) located on the vertical line passing through the gravity centre $\mathrm{G}$ of the voussoir $M_{i} N^{\prime}$ (which extends from angle $\alpha_{i}$ to $\left.\alpha^{\prime}\right)$, the weight $\left(M_{i}+M^{\prime}\right)$ is decomposed into two forces $F^{\prime}$ and $F_{i}$, which form angles $\lambda^{\prime}$ and $\lambda_{i}$ with the vertical direction (Fig. 3a). They are the resultants acting at $M^{\prime} N^{\prime}$ and $M_{i} N_{i}$ joints, respectively, i.e. the joints candidates to slide; while the force acting at joint $M^{\prime \prime} N^{\prime \prime}$ denoted as $F^{\prime \prime}$ is the resultant of force $F^{\prime}$ and weight $\left(M^{\prime \prime}-M^{\prime}\right)$, that is the weight of voussoir $N$ " $M$ " $M$ 'N' (Fig. 3b).

In order to rigorously carry out the analysis, the Authors propose to associate to each of the candidate joints, $\alpha_{i}, \alpha^{\prime}$ and $\alpha^{\prime \prime}$, the system of unity vectors $\left(\boldsymbol{t}_{i}, \boldsymbol{n}_{i}\right),\left(\boldsymbol{t}^{\prime}, \boldsymbol{n}^{\prime}\right)$, and $\left(\boldsymbol{t}^{\prime \prime}, \boldsymbol{n}^{\prime \prime}\right)$, as shown in Fig. 3a,b, which allows to locally identify at each joint the frontiers of Coulomb's domain, defined by the friction cone of angular opening $+f$ or $-f$.

Monasterio considers a mechanism according to which the voussoir containing the key slides downwards without any rotation. He analyzes the resultant reactions whose action lines converge at point $\varphi$ of the barycentric axis in order to ensure that the forces system consisting of weight $\left(M_{i}+M^{\prime}\right)$ and two internal reactions $F_{i}$ and $F^{\prime}$ is characterized by null moment, so that the rotation of the entire voussoir is prevented. It is worthy to note that he takes into account only the inclination of resultant reactions $F_{i}$ and $F^{\prime}$ and not their point of application at joints $\alpha_{i}$ and $\alpha^{\prime}$. Therefore, given the unknown position of the joints that delimit the central voussoir, the criterion adopted by Monasterio does not prevent the possibility that the thrust line touches the boundary of the arch at some points or comes out of it due to insufficient thickness, thus giving origin to a collapse of mixed type or even to the impossibility of equilibrium. In this first part of his analysis this possibility is never examined.

After expressing the modulus of $F^{\prime}$ as a function of total weight $\left(M_{i}+M^{\prime}\right)$ and angles $\lambda_{i}$ and $\lambda^{\prime}$, Monasterio decomposes $F$ ' into two portions: «la primera perpendicular y la segunda paralela a la junta inferior $M$ " $N$ " del trozo $M$ " $N$ '» (Chapter 1, n. 6), by obtaining the destabilizing force $\Delta F_{t}^{\prime}$ provided by the internal reaction $F^{\prime}$ on voussoir $N^{\prime} M$ ':

$\Delta F_{t}^{\prime}=\frac{F^{\prime}}{\cos f}\left[\sin \lambda^{\prime} \sin \left(\alpha^{\prime \prime}-f\right)-\cos \lambda^{\prime} \cos \left(\alpha^{\prime \prime}-f\right)\right]$

$\Delta F_{t}^{\prime}$ is described as the effort by which voussoir $M_{i} N^{\prime}$ tries to move the second voussoir $N$ ' $M$ " along its lower joint in the direction from $M$ " to $N$ " (Fig. 3c). Monasterio observes that the limit condition for the equilibrium with respect to sliding at $M_{i} N_{i}$ and $M^{\prime} N^{\prime}$ joints corre- 
sponds to the limit values: $\lambda_{i}=\frac{\pi}{2}-\alpha_{i}-f$, and $\lambda^{\prime}=\frac{\pi}{2}-\alpha^{\prime}-f$; therefore, the destabilizing action $\Delta F_{t}^{\prime}$ can be rewritten by taking into account these limit conditions.

Monasterio then considers the stabilizing action of weight $M^{\prime \prime}-M^{\prime}$ (Fig. 3d), given by

$\Delta\left(M^{\prime \prime}-M^{\prime}\right)_{t}=\frac{\left(M^{\prime \prime}-M^{\prime}\right)}{\cos f} \cos \left(\alpha^{\prime \prime}-f\right)$
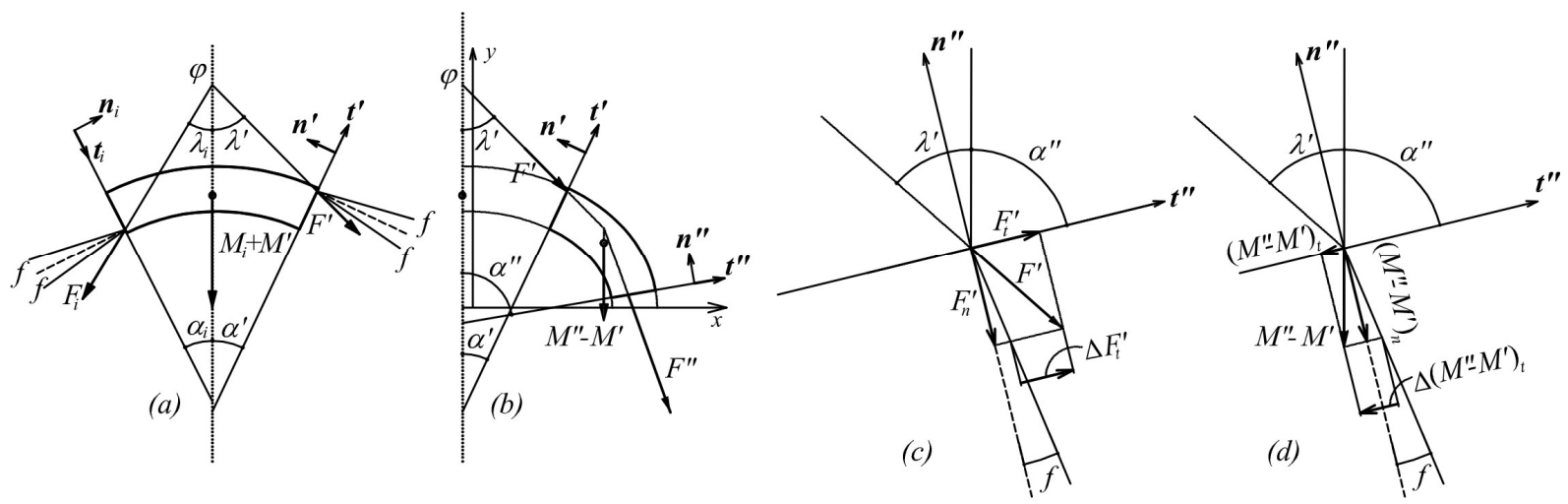

Fig. 3. The forces $F_{i}$ and $F^{\prime}$ acting at joints $\alpha_{i}$ and $\alpha^{\prime}$ (a); the force $F^{\prime \prime}$ acting at joint $\alpha$ ” (b); the destabilizing force $\Delta F_{t}^{\prime}(\mathrm{c})$; the stabilizing force $\Delta\left(M^{\prime \prime}-M^{\prime}\right)_{t}(\mathrm{~d})$.

As a consequence of the actions balance, Monasterio finally states that equilibrium at joint $M$ " $N$ " is guaranteed if $\Delta\left(M^{\prime \prime}-M^{\prime}\right)_{t} \geq \Delta F_{t}^{\prime}$, that is if the following inequality is satisfied:

$\left(M^{\prime \prime}-M^{\prime}\right) \cos \left(\alpha^{\prime \prime}-f\right)-\frac{\left(M_{i}+M^{\prime}\right) \cos \left(\alpha_{i}+f\right)}{\sin \left(\alpha_{i}+f+\alpha^{\prime}+f\right)} \sin \left(\alpha^{\prime \prime}-f-\alpha^{\prime}-f\right) \geq 0$

The collapse condition proposed by Monasterio therefore corresponds to inequality (1) satisfied as equality.

\subsection{A case study: Monasterio's approach and an alternative formulation}

In the following section a case study is examined. Let us consider a non-symmetric masonry arch of unit width, whose geometry is represented in Fig. 4a: it is formed by two sectors of semicircular arches of constant thickness, $h$, and mean radius $R_{i}, R^{\prime}$, respectively. Let $p$ be the specific weight, $f$ the friction angle, and $\mu=\tan f$ the corresponding friction coefficient. The vertical straight line passing through point $A$ is the $y$ axis introduced by Monasterio in his analysis. The joints at the arch's springing are defined by angles $\beta_{i}=\pi / 3$ and $\beta^{\prime}=\pi / 2.3$, respectively (Fig. 4a). Furthermore, ratios $h / R_{i}=3 / 5, h / R^{\prime}=1$ are assumed, so that $R^{\prime} / R_{i}=3 / 5$.

Let denote as $R\left(\alpha_{i}, \alpha^{\prime}, \alpha^{\prime \prime}\right)$ the dimensionless quantity obtained by dividing the first member of inequality (1) by $p \cdot\left(R^{\prime}\right)^{2}$.

According to (1), equilibrium is guaranteed if $R\left(\alpha_{i}, \alpha^{\prime}, \alpha^{\prime \prime}\right) \geq 0$, with reference to the pure sliding mechanism under examination.

The values of $R$ depend on $\alpha_{i}, \alpha^{\prime}, \alpha^{\prime \prime}$. The study of inequality (1) can be carried out by fixing, by attempt, the value of the lower joint sliding towards the outside, namely, the joint $\alpha$ ". As a first trial, $\alpha^{\prime \prime}=\beta^{\prime}=\pi / 2.3=78.2609^{\circ}$ is assumed, since Monasterio himself suggests considering this joint. By posing the value of the friction coefficient equal to $\mu=0.35$, $R\left(\alpha_{i}, \alpha^{\prime}, \alpha^{\prime \prime}=\beta^{\prime}\right)$ remains always positive by reaching its minimum value: 
$\min (R)=0.254133>0$,

for $\alpha_{i}=33.12^{\circ}$ and $\alpha^{\prime}=18.76^{\circ}$; the corresponding trend $R\left(\alpha_{i}=33.12^{\circ}, \alpha^{\prime}, \alpha^{\prime \prime}=\beta^{\prime}\right)$ is represented in Fig. 4b, where the minimum value is attained at point $\mathrm{A}$, for $\alpha^{\prime}=18.76^{\circ}$.

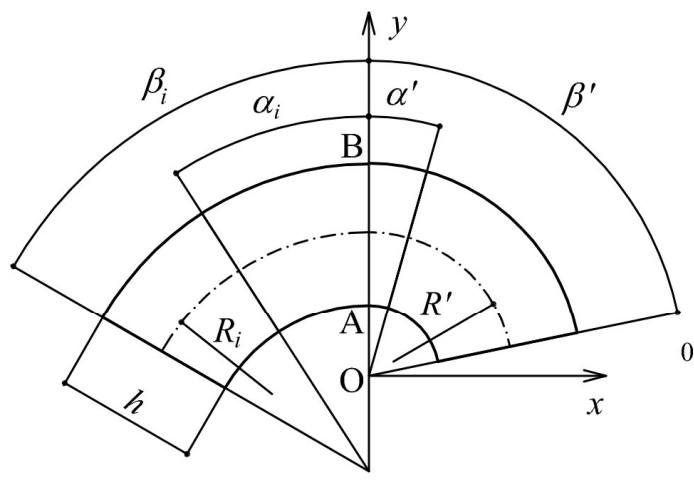

(a)

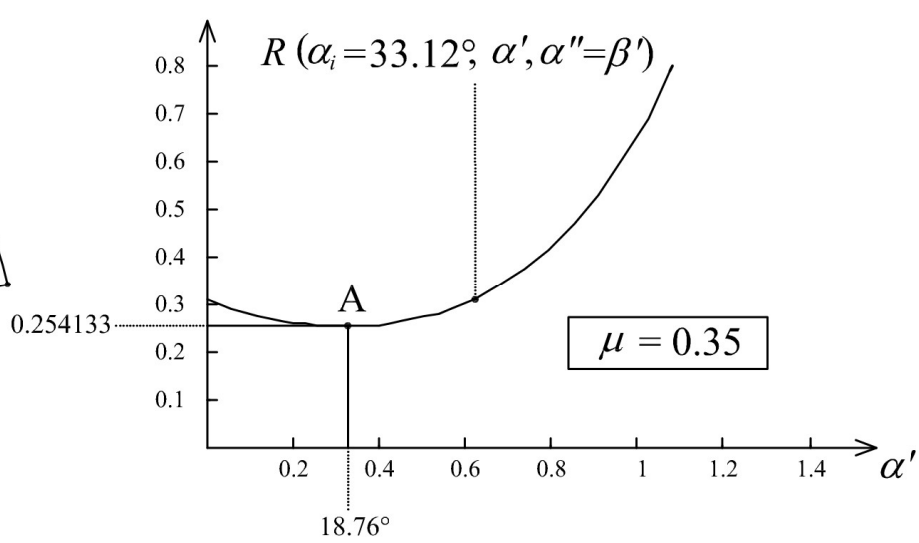

(b)

Fig. 4. The case study (a); the sliding equilibrium condition according to Monasterio, for $\mu=0.35$ (b).

By decreasing the value of the coefficient of friction up to $\mu=0.25490905$, we obtain min $(R)=0$, for $\alpha_{i}=33.8075^{\circ}$ and $\alpha^{\prime}=16.1539^{\circ}$ : This limit condition corresponds to the graph of Fig. 5a, where $R\left(\alpha_{i}=33.81^{\circ}, \alpha^{\prime}, \alpha^{\prime \prime}=\beta^{\prime}\right)$ is plotted as a function of angle $\alpha^{\prime}$. The minimum is attained at point $\mathrm{A}$, for $\alpha^{\prime}=16.1539^{\circ}$. For this value of the friction coefficient $(\mu=$ 0.25490905), according to the analysis of Monasterio, the mechanism represented in Fig. $5 \mathrm{~b}$ occurs.

By decreasing the value of the friction coefficient up to $\mu=0.25490905$, the value min (R) $=0$ is obtained for $\alpha_{i}=33.8075^{\circ}$ and $\alpha^{\prime}=16.1539^{\circ}$ : this limit condition corresponds to the graph of Fig. 5a, where $R\left(\alpha_{i}=33.81^{\circ}, \alpha^{\prime}, \alpha^{\prime \prime}=\beta^{\prime}\right)$ is plotted with its minimum again attained at point A. Therefore, according to the Monasterio's analysis, $\mu=0.25490905$ represents the value of the friction coefficient, for which the mechanism represented in Fig. $5 b$ occurs. 


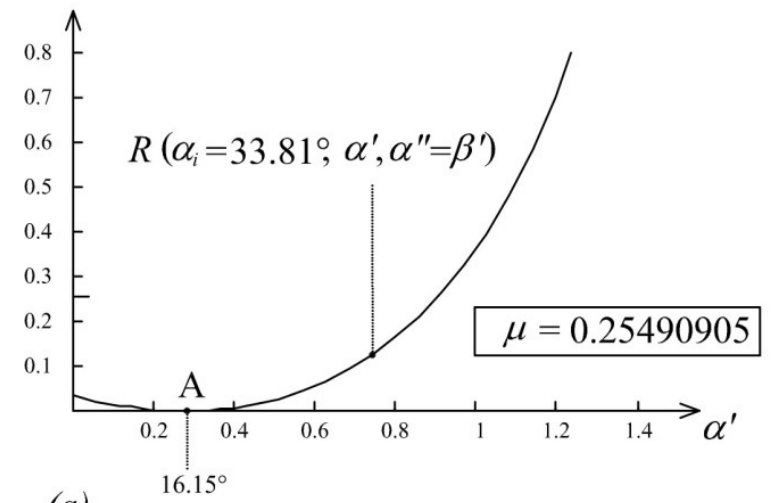

(a)

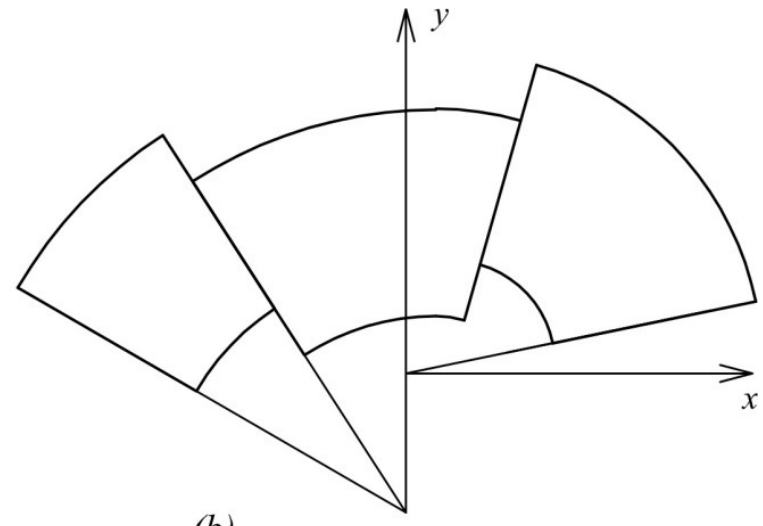

(b)

Fig. 5. The limit sliding equilibrium condition according to Monasterio (a); the corresponding collapse mechanism (b).

An alternative formulation of the problem can be carried out in terms of a lower bound approach; in analogy to Coulomb's method, the internal forces acting at the key joint can be assumed as unknown variables. However, differently from the equilibrium analysis of symmetric arches, the case of non-symmetric arches requires that, not only the thrust $H$, but also the shear force $T$ is taken into account (Fig. 6a).

By posing the specific weight $p$ as $p=1 /\left(R^{\prime}\right)^{2}$, the dimensionless thrust $\eta$ and shear force $\tau$ will be then considered. The statically admissible solutions (with reference to sliding equilibrium) are represented by points $(\eta, \tau)$ belonging to the dashed area in Fig. 6b, where $\mu=0.35$ is assumed as an example; such area would shrink to a single point in correspondence to the limit value of the friction coefficient.
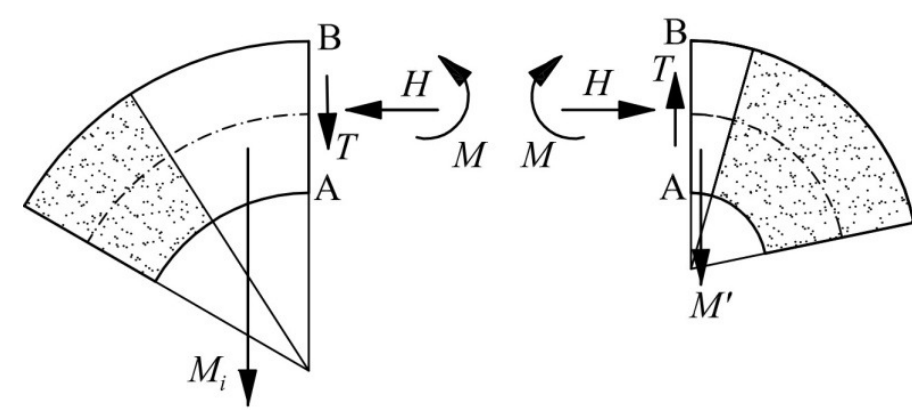

(a)

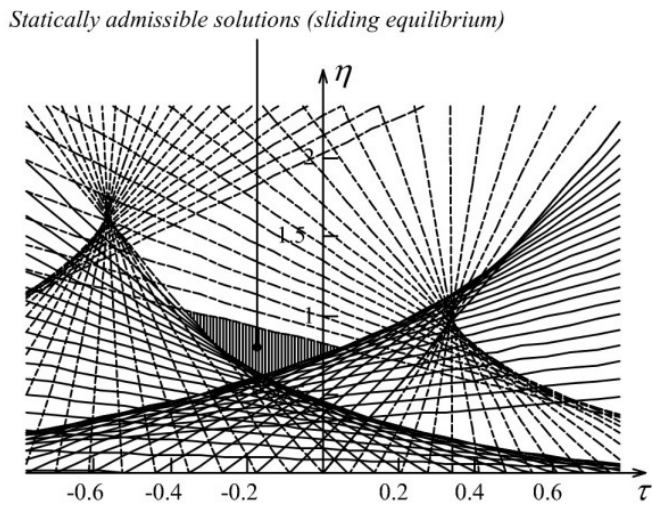

(b)

Fig. 6. An alternative formulation: thrust $H$ and shear force $T$ acting at the key joint (a); the statically admissible solutions in the plane $(\eta, \tau)$, with reference to sliding equilibrium (b).

For the sake of brevity, in this paper only sliding equilibrium has been considered. The complete alternative formulation consists in identifying the domain that guarantees the equilibrium with respect to rotational mechanisms and, in a second step, its intersection with the domain that guarantees sliding equilibrium. In a forthcoming paper the detailed procedure will be described: the present case study will be analyzed in order to define the dependence of the various collapse mechanisms on thickness and friction. In order to place Monasterio's approach in relation to the modern limit analysis, it can be anyway interesting to recall some 
considerations on the masonry standard and non-standard behavior. In the presence of finite values of the friction, the normality rule characterizing a standard behaviour of the material does not hold, so that some static admissible solutions identified through the equilibrium method could correspond to a mechanism with relative sliding. In this case, the collapse mechanism is not only undetermined, but also not necessarily unique, except for particular cases such as symmetric arches [5, 7-10]. For non-standard behavior, the static approach requires that equilibrium with respect to the rotational collapse is guaranteed, as necessary condition in order to activate any mechanism with sliding [7]. The limit analysis for pure sliding should be preceded by that concerning mechanisms with pure rotation and mixed mechanisms with rotation and sliding.

As already stated, the approach proposed by Monasterio, conversely, differentiates itself from the static one proposed by Coulomb, since the starting point of his analysis concerns the a priori identification of some plausible collapse mechanisms, by defining a posteriori the conditions required for their activation; therefore, the procedure can be placed in an upper bound framework, by overcoming some difficulties inherent in both the static and kinematic approaches for non-standard materials.

\section{CONCLUSIONS}

- The kinematic approach proposed by Monasterio is substantially correct, although clear considerations on the global equilibrium of the arch are lacking.

- The completeness of the various collapse mechanism by him considered is an important issue, to be clarified in a future research.

- Monasterio's manuscript is characterized by its very and somehow extremely courageous analysis in relation to the new proposed subject, the collapse modes occurring in a nonsymmetric arch. It appears to be as a new research frontier on the masonry arches mechanics, considering the time in which the analysis was developed.

\section{ACKNOWLEDGMENTS}

Financial support from the University of Pisa under programme PRA 2018-2019, project "Modellazione multi-scala in ingegneria strutturale" ("Multi-scale modeling in Structural Engineering") is gratefully acknowledged.

\section{REFERENCES}

[1] Huerta, S., Foce, F. 2003. Vault theory in Spain between XVIII ${ }^{\text {th }}$ and XIX ${ }^{\text {th }}$ century: Monasterio's unpublished manuscript "Nueva teorica sobre el empuje de bovedas", Proceedings of the First International Congress on Construction History, Madrid. January 20-24, 2003, S. Huerta (ed.), Madrid: I. Juan de Herrera, ETSAM, 2003, 11551166.

[2] Coulomb C.A. 1776. Essai sur une application des règles de maximis et minimis à quelques problèmes de statique, relatifs à l'architecture. Mémoires de Mathématique et de Physique, Présentés à l'Académie Royale des Sciences par Divers Savans 7 (année 1773):343-382

[3] Heyman J. 1972. Coulomb's memoir on statics, Cambridge.

[4] Heyman, J. 1969. The safety of masonry arches, International Journal of Mechanical Sciences, 11, 363-385. 
[5] Sinopoli, A., Corradi, M. and F. Foce. 1997. A Modern Formulation for Pre-Elastic Theories on Masonry Arches, Journal of Engineering Mechanics, ASCE, 204-213.

[6] Sinopoli, A. 2002. A Re-examination of Some Theories on Vaulted Structures: The role of Geometry from Leonardo to De La Hire, Becchi A., Corradi M., Foce F. and Pedemonte O. (eds.), TOWARDS A HISTORY OF CONSTRUCTION, series Between Mechanics and Architecture, Birkhäuser, Basel, 601-624.

[7] Sinopoli, A., Aita, D. and F. Foce. 2007. Further Remarks on the collapse of masonry arches with Coulomb Friction, Proceedings of the 5th International Conference on Arch Bridges. P. B. Lourenço, D. V. Oliveira, and Portela A. (eds.), Multicomp, Guimaraes, 2007, 649-657.

[8] Casapulla, C., Lauro, F. 2001. A simple computation tool for the limit-state analysis of masonry arches. In: Proceedings of the 5th International Congress on Restoration of Architectural Firenze Heritage 2000, 2056-2064.

[9] Aita, D., Barsotti, R., Bennati, S. 2015. Notes on limit and nonlinear elastic analyses of masonry arches. In: Aita, D., Pedemonte, O., Williams, K. (eds.) Masonry Structures: Between Mechanics and Architecture, pp. 237-264. Birkhäuser, Basel. https://doi.org/10.1007/978-3-319-13003-3_9. Print ISBN 978-3-319-13002-6, Online ISBN 978-3-319-13003-3

[10] Aita D., Barsotti R., Bennati S. 2019. Looking at the collapse modes of circular and pointed masonry arches through the lens of Durand-Claye's stability area method, Archive of Applied Mechanics. https://doi.org/10.1007/s00419-019-01526-Z 